KONSTANTIN L. LiDin

Mary A. SumenKova

Irkutsk State Railway University, Russia

\title{
Competitiveness and the emotional essence of a region image
}

The current state of economic theory is characterized by a rapid growth of interest to socio-psychological aspects of financial streams structure - to so-called behavioral finance. The theme is especially actual for the countries whose economy is demonstrating fast, but non-uniform growth (the BRIC group: Brazil, Russia, India, and China). From the behavioral economy point of view, the image of a region becomes more and more important. Image has a strong influence at forming the demographic situation, at the level of investment attractivity and some other aspects of competitiveness of a region. Image is mostly important for touristic business development.

Key to understanding the essence of the phenomenon of behavioral finance is inclusion of human emotions into the sphere of economic analysis.

Cost of emotions is great enough. So, buying the ticket at cinema, the spectator actually buys possibility of experience of emotions valuable to it during one and a half to two hours. Thus, the price of positive emotions in Russian market of entertainments appears to be equal to $60-300 \mathrm{rbl}$./hour. Actually the cost of emotions even above the ticket price includes the risk price in cinema that the film will not be pleasant.

There are whole areas of the modern market in which the emotional aspect of economic behavior initially plays a paramount role. These are areas of manufacture and distribution of luxury goods, show business and the so-called market of cultural values - cinema, theatre, music and so on. The total volume of financial streams proceeding through these markets, reaches an order of $\$ 1011$ - 1012 / year that is comparable with such ,rational” markets, as oil, metals or real estate. According to a well known audit company PricewaterhouseCoopers the cumulative world turn of show business and mass-media in 2007 has exceeded $\$ 1,5.1012$, and by 2011 will reach $\$ 2.1012$.

Emotions of pleasure, pride and interest use mass demand in the markets. However not smaller demand exists on the emotions which can be perceived as negative - fear, uneasiness, gloating, anger. Such a version of fear as passion and such versions of anger as boldness, bravery and impudence are the basic goods of gaming. The gaming annual turnover does not give in to exact definition, but under the indirect data it is possible to assert that its scale makes more than $\$ 1011$ a year.

The influence of emotional essence of a region image at the regional economy has been the least studied. There exist numerous data on the interconnection between unconscious emotional motivations and taking administrative decisions, including those in the sphere of 
managing investment streams. However, by now, emotionally-shaped aspects have not been considered enough in the models of regional economic development. The reason of this situation is the lack of exact methods of measurement of emotional essence of a region image.

Throughout the last fifteen years we have developed the methods allowing to measure, with high objectivity and accuracy, the emotional essence of images. First of all, the given methods are intended for studying of the most widespread forms of image - verbal and visual ones. Both techniques exist in the form of computer programs which provide high speed and allows to analyze big amounts of initial data.

The image of Eastern Siberia has been analyzed on the basis of Internet materials.

In first half of XX-th century there was variety of the considerable researches devoted to a psychological phenomenon of synethesia. The given phenomenon consists that the signal received on one of perceptive channels (modalities), is endured as if it is received on all channels simultaneously.

There are six basic channels of reception of the information on world around (perceptive channels or modalities). The Dominant role is played by sight, on this channel the person receives about $80 \%$ of the information. On the second place settles down kinaethetic (muscular) feeling, allowing to distinguish heavy from a lung, strained conditions from weakened, to feel movement and an immovability and so on. The third place on volume of the transferred information is occupied with the tactile (skin) modality, allowing to feel heat and a cold, smooth and rough, other properties of surfaces. The hearing takes only the fourth place. Taste and sense of smell are developed at the person so badly that signals on these two modalities all time are confused among themselves. We tell «a sweet smell» or ,a spiciness taste” though ,sweet” - the taste characteristic, and spices are characteristic just a smell. Therefore many researchers do not divide these two modalities, and consider them as a uniform information channel - odoral.

Except external displays of emotions, formation of their image influences also internal experiences. Emotional stances are connected with certain corporal sensations (perceptions). For example, emotion «interest - excitation» is endured as the general increase of a tone of the organism. Colour sight and a world picture as a result becomes aggravated looks more colour and bright. The raised muscular tone is endured as pressure and dynamics (intense movement). The raised tone of a skin is endured as sensation of heat and a touch of a rough surface. The raised tone of hearing shifts a perception strip in area of higher frequencies sounds are perceived more sonorous and loud. Becomes aggravated as well a susceptibility to odoral stimuls therefore smells and tastes are perceived by more spicy. Sensitivity to sweet taste increases.

On the contrary, emotion of grief is connected with organism depressions. In a depression colour sight is oppressed, and the world picture becomes black-and-white. The lowered muscular tone is endured as the languid, weakened and motionless condition. The lowered tone of a skin gives sensation of a cold and a smooth surface. The lowered tone of hearing subjectively shifts perception in area of silent and deaf sounds. Smells and tastes are perceived more fresh and is bitter-salty.

Emotional conditions of fear are connected with chaos experience. The fear is easing or loss of an internal rhythm in which the organism functions. As a result of chaotic movements of eyes in a condition of fear the world picture looks more motley and washed away. Chaotic excitation of muscles is endured as a convulsive, unstable condition. Chaotic skin experience is similar to a touch of a sharp, cutting or pricking subject. Chaotic sound experiences is dis- 
cord, creaking and not musical sounds. Experiences of fear in flavouring and smelt mode are formed as follows: in a condition of strong fear stomach spasms throw out gastric juice in a mouth. Its sour and sharp taste (copper test) is and there is a taste of fear.

Emotional experience of an order is connected with emotion of conscience. Corresponding to it perceptive signs are opposite to what are characteristic for fear.

Four base emotions correspond to two key parameters of the information stream proceeding through sense organs. The pair of emotions "grief - interest" corresponds to intensity of this stream. The grief corresponds to the minimum intensity, interest-maximum. The pair of emotions "fear - conscience" reflects parameter of orderliness of an information stream. The fear corresponds to a chaotic stream, conscience - coherent and natural. Intensity and orderliness parameters it is mutual ortogonal and form two-dimensional space of emotions, as is shown in fig. 1:

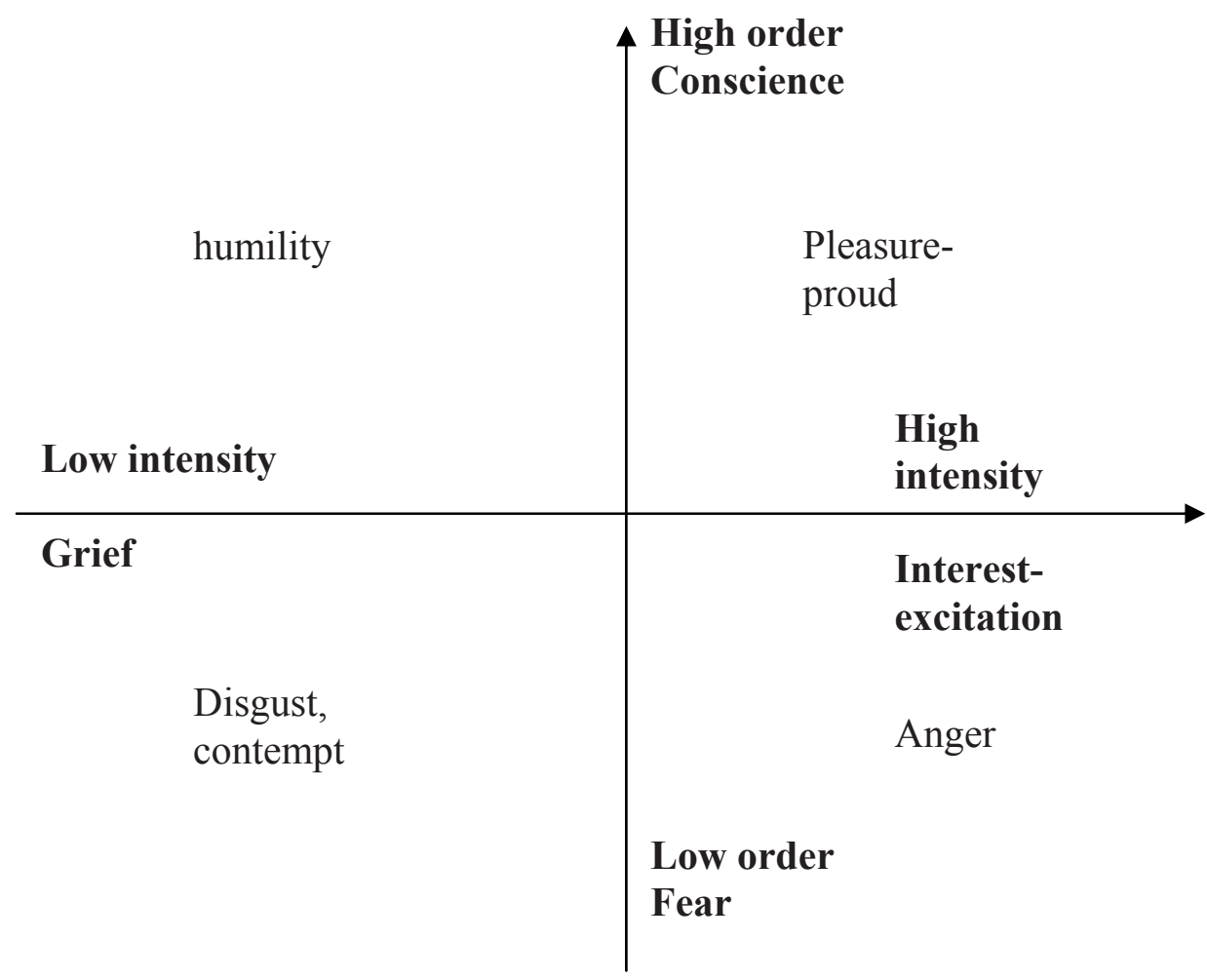

On each axis of space of emotions there is a natural limit of intensity. No emotion can accrue beyond all bounds. So, limiting intensity of emotion interest-excitation is called „hysterics", and the further increase of intensity of an information stream is impossible because of an excessive intensification of all processes in an organism. Other-wordly excitation causes literal „overheat” of an organism and leads to its destruction. On the contrary, limiting emotion grieves (despair) so slows down organic processes that also is incompatible with life. The other-wordly fear (panic) and conscience (repentance), and also intermediate emotions similarly kills: limiting anger (frenzy), limiting disgust (nausea), limiting humility (shame) and pleasure-pride (ecstasy). 
The area near to crossing of axes (a zero of co-ordinates) corresponds to a condition of apathy, indifference.

Definition of co-ordinates of the emotional maintenance of the image was spent by us by means of the following perceptive signs:

1. Co-ordinate on an axis of ordinates

1.1. Differential «achromatic - spectral». Even at common sense level communication of grief with grey, achromatic perception of the world, and interest conditions - with colour, iridescent is clear. This thesis has been checked up by us on the big art criticism material and has completely proved to be true. The it is less colour in the picture, the it is more sad perceived;

1.2. Differential «cold - hot». In spite of the fact that images are perceived visually, synethetic experience allows to divide spectral tone on cold and hot. The cold concern violet, dark blue and green. To warm - yellow, orange and red. The quantitative parity of those and others allows to define general cold or hot „key” of the image;

1.3. Differential «monophonic - contrast». Conditions lowered stenicity (grief) are characterised by decrease in ability of an eye to distinction of shades. Therefore experience of emotions of grief, melancholy, a grief are accompanied by ,fading” of a picture of the world, loss of sonorous contrast of tones by it. Oppositely, interest to the surrounding forces to see all around more contrast, various and mobile;

1.4. Differential «dim - bright». Brightness and contrast are similar at direct perception, but considerably differ at the exact analysis. If contrast is defined as the maximum distinction between the tones which are present at the image as brightness is called level of difference of tones of a picture from average grey tone;

1.5. Differential «smooth - rough». The tactile sensation of roughness arises on synethetic to the mechanism as a result of visual perception of the invoice small heterogeneities of the images (,grain”, a raster);

1.6. Differential «pessimistic - optimistic». The given differential concerns to composite and reflects properties of specific area of the image - the optical centre. As art criticism researches, this area located over crossing of diagonals of a rectangular shot show, considerably influences the general emotional key of a picture. If the area of the optical centre is painted is more light, than a picture on the average all image receives the raised, vigorous, optimistic sounding. On the contrary, the dark stain in the optical centre shifts the image in sad, pessimistic area.

Each differential is graduated in conditional points from zero to hundred so the apathy point is necessary on value of 50 conditional points.

2. On an axis of abscisses we also have allocated some semantic differentials:

2.1. Differential «any - accord». As an accord combination of tones is called such which corresponds any of so-called classical colour chords. The combination of tones opposite on properties makes impression of diversity, disorder. Accord colour combinations corresponds to the ordered conditions of the top semiplane of space of emotions

Differentials of an axis of abscisses also are graduated in conditional points from zero (strongest fear, panic) to hundred (strongest conscience, repentans).

Application of a technique of semantic differentials has allowed us to algorithm and to charge to the computer the process of the analysis of images for the purpose of definition of their emotional maintenance. Developed program "ImageExpert" allows to process digital 
images with high speed that gives the chance to analyze the big files of pictures - tens and even hundreds separate shots.

The important source of the information on world around is the verbal channel. We have developed a special technique of the frequency content-analysis for measurement of the emotional essence of texts. The technique includes following steps:

1. The lemmas designating emotional conditions are allocated;

2. To each lemma values in the conditional points, reflecting intensity of the emotion are appropriated;

3. In the investigated text calculation of quantity of each of lemmas is made culated

4. The resulted frequency of presence of each of lemmas under the formula (1) is cal-

$$
\mathrm{Ni}=(\mathrm{ni} / \mathrm{k}) * 106-\mathrm{Mi}
$$

$\mathrm{Ni}$ - the resulted rate of $\mathrm{i}$ lemmas;

ni - quantity of words of the i lemmas, found out in the investigated text

$\mathrm{k}$ - total of words in the investigated text (text volume)

$\mathrm{Mi}$ - rate of i lemmas on one million words of English language (ipm) according to the frequency word book ${ }^{1}$. Rate of $i$ lemmas was defined as the sum of rates of all word forms containing the given lemma;

5. Intensity of presence of each base emotion in the text under the formula (2) is calculated:

$$
\mathrm{Ij}=\sum(\mathrm{Nj}, \mathrm{i} * \mathrm{bj}, \mathrm{i})
$$

$\mathrm{Ij}$ - intensity of presence of $\mathrm{j}$ emotions in the text

$\mathrm{Nj}, \mathrm{i}$ - the resulted frequency of the i lemmas, concerning $\mathrm{j}$ emotion

bj, $\mathrm{i}$ - intensity of the $\mathrm{j}$ emotion expressed by $\mathrm{i}$ lemma.

The total amount of initial data was about 400 thousand words and 5 thousand pictures. The analysis of texts and pictures has shown that the perception of the region shows a high similarity for the inhabitants of Western and Eastern Europe, of the USA, Australia or China. The spectrum of emotions shifts towards chaotic and sthenic stances of fear, anger and interest. As a whole, the image of the region is close to the archetypical image of a Hero. Monitoring of the data throughout last five years has shown the drift of the image from the archetype of a Wild (Monstrous) Hero to the archetype of a Wise Hero. The regional image, thus, sharply distinguishes Eastern Siberia from the tourist objects of more traditional character. Visiting Eastern Siberia is endured as a dangerous and exciting adventure that forms specific expectations for both tourists and potential regional investors. The researches data have been used in working out the development strategy of the region and the development policy of touristic business.

We have as well analyzed the Internet materials devoted to Kraków as a tourist object. Despite rather small volume of the initial data (about 10 thousand words and 1000 pictures), unexpected results have been received.

1 M. Davies, D. Gardner, A Frequency Dictionary of Contemporary American English, Routledge, Taylor and Francis, 2010, 368 pp. 
The emotional spectrum of statements of Kraków visitors (on the materials of English language tourist blogs) contains a relatively high share of emotions of grief, fear and anger. It is possible to assume that for tourists from Central and Western Europe, visiting Kraków is emotionally somehow close to visiting Siberia, both are thought of as "East" for them. The degree of ",heroism” needed for a trip to Poland, is, certainly, much lower than for visiting Eastern Siberia, but archetypically, the base of images of the two regions contains something common.

On the contrary, the emotional essence of advertising materials is strongly shifted towards emotions of interest and pride. The advertising materials devoted to many other tourist magnets of Europe, America or Asia have similar spectrums. As a result, the image of Kraków is deprived of individuality. Uniqueness of the city is not reflected.

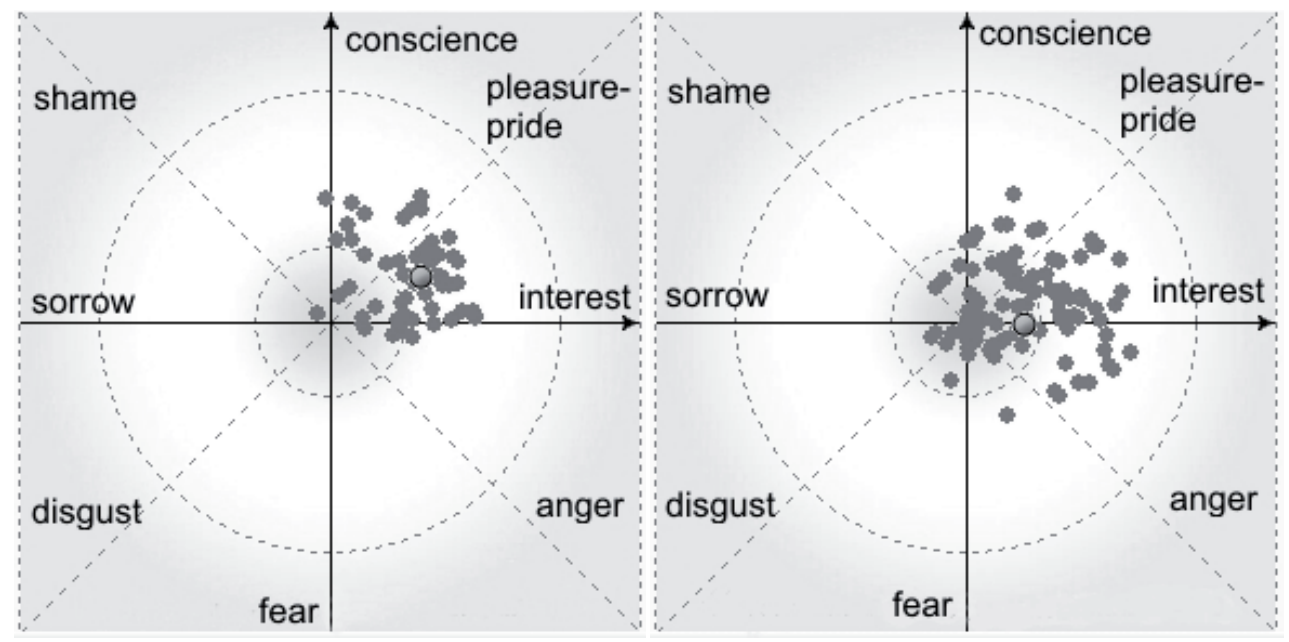

Fig. 2. Comparative position of the emotional essence of photos of Kraków concerning base emotions

Each point corresponds to one image. The allocated point designates the centre of the claster.

At the left - the claster, corresponding to advertising photos of Kraków.

On the right - the one on the basis of photos made by tourists and placed in Internet.

The emotions expressed by tourists, are more various and more chaotic.

In summary, it is necessary to notice that the narrow and monotonous emotional spectrum of advertising is capable to push away a potential tourist. The emotional maintenance of advertising materials forms quite certain expectations of a potential buyer (tourist). Discrepancy of the emotions promised by advertising, with real experiences leaves impression of the deceit, not justified expectations. In a long-term prospect, such an advertising inevitably reduces tourist appeal and competitiveness of region. 

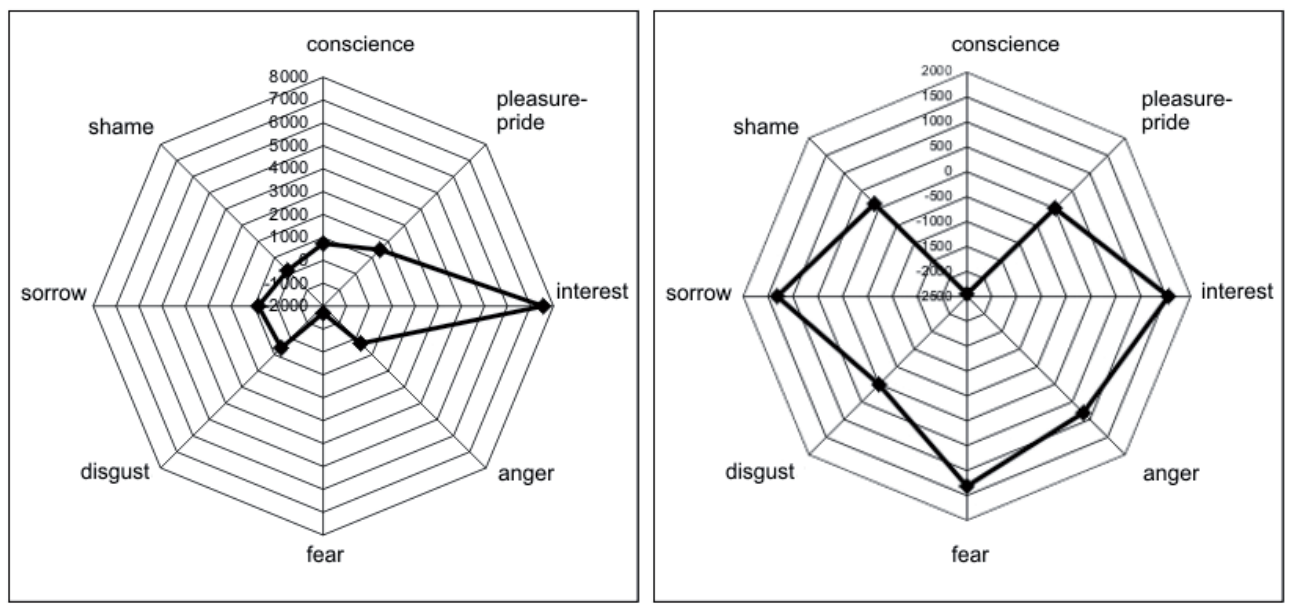

Fig. 3. Comparative result of measurement of the emotional essence of texts by the method of frequency content-analysis

At the left - result of the analysis of advertising texts about Kraków.

On the right - result of the analysis of the texts placed in Internet by tourists, having visited Kraków.

The emotions expressed by tourists are much more various and more intensive. Impression of orderliness (emotion conscience) is much less, than in advertising. But the emotions connected with experience of adventures (passion, fear, boldness) - are much more intensive.

\section{REFERENCES}

Лидин К.Л. Имидж Сибири в сегодняшней Западной Европе // Регион на перекрестке Востока и Запада: глобализация и конкурентоспособность. Коллективная монография. - М.: ТЕИС, 2003. - C. 285-290.

Лидин К.Л. Исчисление эмоций/К.Л. Лидин//Равновесные модели экономики и энергетики: Труды Всероссийской конференции и секции Математической экономики ХІІІ Байкальской международной школы-семинара «Методы оптимизации и их приложения».- Иркутск: Изд-во ИСЭМ СО РАН, 2005. - С. 83-89

Лидин К.Л. Психология имиджа. Монография. - Иркутск: РИЦ ИГУ, 2005.- 103 с.

Marks L.E. \& Arieh Y., 2006, Differential effects of stimulus context in sensory processing. European Review of Applied Psychology, 56, p. 213-221.

Osgood Ch.E., Suci G., 1957, Tannenbaum, The Measurement of Meaning. University of Illinois Press.

Osgood Ch.E. \& Tzeng O. (eds), 1990, Language, Meaning, and Culture: The Selected Papers of Ch.

E. Osgood. Praeger Publishers. 


\section{Competitiveness and the emotional essence of a region image}

From the behavioural economy point of view, the image of a region becomes more and more important. Image has strong influence on forming the demographic situation, at the level of investment attractiveness and some other aspects of competitiveness of a region. Image is mostly important for tourist business development.

Throughout the last fifteen years we have developed methods that enable measuring the emotional essence of images with high objectivity and accuracy. First of all, the given methods are intended for studying the most widespread forms of image - verbal and visual ones. Both techniques exist in the form of computer programmes which provide high speed and enable analysing big amounts of initial data.

The emotional spectrum of statements of Kraków visitors (on the materials of English language tourist blogs) contains a relatively high share of emotions of grief, fear and anger. It is possible to assume that for tourists from Central and Western Europe, visiting Kraków is emotionally somehow close to visiting Siberia, both are thought of as "East" for them.

On the contrary, the emotional essence of advertising materials is strongly shifted towards emotions of interest and pride. The advertising materials devoted to many other tourist magnets of Europe, America or Asia have similar spectrums. As a result, the image of Kraków is deprived of individuality. Uniqueness of the city is not reflected.

The narrow and monotonous emotional spectrum of advertising can push away a potential tourist. The emotional maintenance of advertising materials forms quite certain expectations of a potential buyer (tourist). Discrepancy between the emotions promised by advertising and the real experience leaves an impression of deceit, not justified expectations. In a long-term prospect, such advertising inevitably reduces tourist appeal and competitiveness of the region.

Doc. Konstantin L. Lidin

Mary A. Sumenkova

Irkutsk State Railway University, Russia

e-mial: lidinkl@hotmail.com 